Phosphorus and Sulfur, 1983, Vol. 18 pp. 7-10 $0308-664 X / 83 / 1801-0007 / \$ 18.50 / 0$
(C) 1983 International Union of Pure and Applied Chemistry Printed in the United States of America

\title{
1,2- AND 1,3-DIPHOSPHETANES FROM ALKYLIDENEPHOSPHINES
}

GERD BECKER, WINFRIED BECKER, GUDRUN UHL, WERNER UHL, AND HANS-JÜRGEN WESSELY

Institut für Anorganische Chemie der Universität Stuttgart, Pfaffenwaldring 55, D-7000 Stuttgart 80

Alkyl- or arylbis(trimethylsilyl)phosphines as well as tris(trimethylsilyl)phosphine and the corresponding arsines react with acyl chlorides to give [1-(trimethylsiloxy)alkylidene]phosphines 1 and-arsines 2; most of their 2,2-dimethylpropylidene derivatives are thermally stable at room temperature. With the same class of phosphines as starting compounds and carbon disulfide [bis(trimethylsilylsulfano)methylidenelphosphines 3 are formed, whereas [(dialkylamino)methylidene]- $\underline{4}$ and [diarylmethylidene]phosphines $\underline{5}$ or the corresponding arsines 6 and $\underline{7}$ can be obtained from acyl amides or ketones. 1

In order to elucidate factors responsible for the high thermal stability of these alkylidenephosphines and -arsines, especially to test the shielding effect of bulky groups, [1-(trimethylsiloxy)alkylidene] compounds with small substituents bound to the $E=C$ group were studied:

Keeping the mixture of $(E)$ - and $(Z)-[2,2$-dimethy1-1-(trimethy $1-$ siloxy)propylidene] phosphine obtained from bis(trimethylsilyl) phosphine and 2,2-dimethylpropionyl chloride, for two or three weeks at $+20^{\circ} \mathrm{C}$ in diffuse daylight, slowly large, well-shaped crystals of 2,4-di (tert-butyl)-2,4-bis (trimethylsiloxy)-1,3-diphosphetane 8 start to precipitate. As a result of strong intramolecular repulsions which are verified by long endocyclic P-C distances of about $190 \mathrm{pm}$, the ring system is strained to such an extent that in solution rapid decomposition to the monomers occurs (eq. (1)).2 


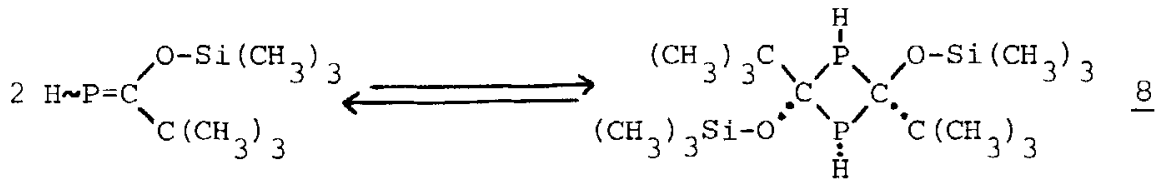

As a result of longer As-C distances there is left more space for bulkier substituents in 1,3-diarsetanes. In contrast to the corresponding phosphines which are completely stable, methyl-, ethyl-, and benzyl[2,2-dimethyl-1-(trimethylsiloxy) propylidene]arsine dimerize, especially when exposed to UV-irradiation to give 1,3-diarsetanes 9 of molecular symetry $\mathrm{C}_{2 \mathrm{v}}$. In this case, complete monomerization is observed for the molten compounds. ${ }^{3}$

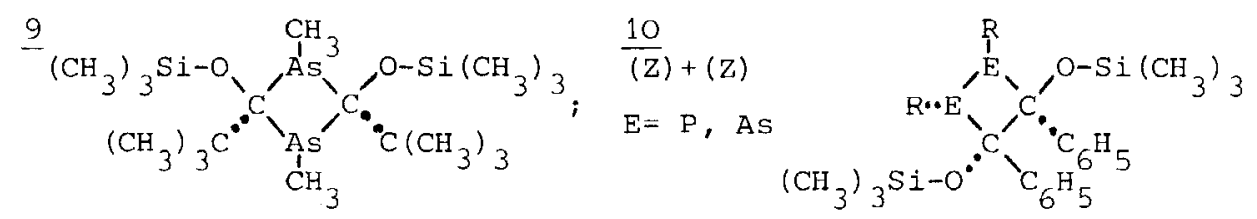

Thermally unstable [1-(trimethylsiloxy)alkylidene]phosphines and -arsines one also comes across when the shielding effect of the bulky tert-butyl group which has been introduced with 2,2-dimethylpropionyl chloride, is abandoned and when benzoyl chloride is used as acyl halide.

with careful studies of some alkyl derivatives the rate of reaction was shown to be strongly increased by traces of acid from the acyl halide. Using ordinary, distilled benzoyl chloride the (Z)isomer is formed very quickly so that there is left enough time for the dimerization of this compound. $x$-ray structure determinations of the iso-propyl compounds $10(Z)+(Z)$ gave three important results: Not a 1,3- but a 1,2-diphosphetane or a 1,2-diarsetane with a direct $\mathrm{E}-\mathrm{E}$ bond has been formed. The configuration of the monomers can still be recognized in the dimers. With the constitution found it is easily understood that these cyclic systems decompose to give (E)-1,2-bis (trimethylsiloxy)-1,2-diphenylethene and cyclopolyphosphines or -arsines. If benzoyl chloride used is carefully freed from acid impurities the rearrangement of the (E) - to the 
(Z)-alkylidenephosphine - (E)-alkylidenearsines are still unknown is retarded and competitive dimerization reactions can occur. Finally one isolates a mixture of two different 1,2-diphosphetanes marked with $10(Z)+(E)$ and $10(E)+(E) \quad(R=$ benzyl). 4
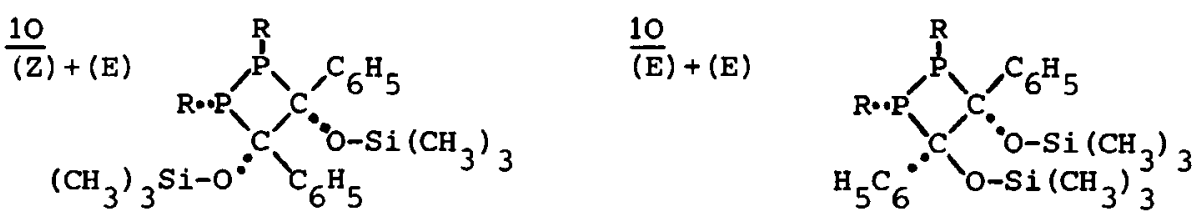

Similarly the dimerization of [diphenylmethylidene]-(iso-propyl)phosphine leads to a 1,2-diphosphetane, whereas the benzyl derivative gives a mixture of the 1,2- and the 1,3-compound. In this context the formation of the 1,2-diphosphet-3-en-1-sulfide 11 from an (N,N-dimethylthiocarbamoyl) trimethylsilylphosphine must be mentioned (eq. $(2))^{4}$

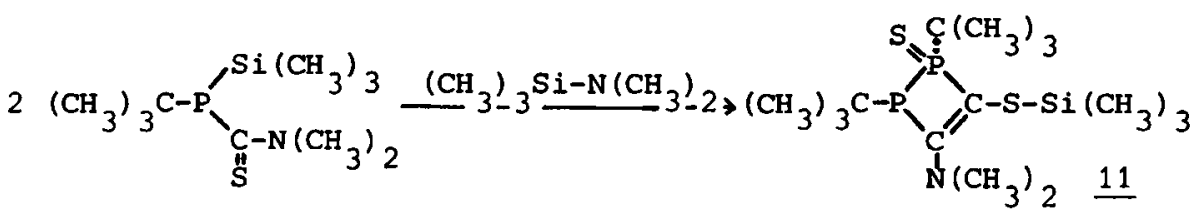

From all these results we conclude that alkylidenephosphines and -arsines with bulky substituents at the pnicogene, but small ones at the carbon atom of the $E=C$ group show the tendency to form 1,2compounds. Obviously this arrangement with a long E-E and a 'short' $\mathrm{C}-\mathrm{C}$ single bond can reduce intramolecular repulsions much better than a ring system with four equal E-C bonds of intermediate length.

In (E)-[dialkylamino)methylidene]phosphines or -arsines an interaction between the free electron pair at nitrogen and the $\pi$-bonding system of the $E=C$ group $(E=P, A s)$ contributes to the stability of these compounds. But here, too, the shielding effect of bulky substituents can be clearly recognized in that the (tert-butyl) - and the mesitylphosphine remain monomers, whereas the methyl and phenyl compound slowly form dimers. $\mathrm{x}$-ray structure determinations show the dimeric compounds $12\left(\mathrm{R}=\mathrm{C}_{6} \mathrm{H}_{5}\right.$ or $\left.\mathrm{CH}_{3}\right)$ to be 1,3-diphosphetanes 
of approximate $\mathrm{C}_{2 \mathrm{v}}$-symmetry. ${ }^{5}$ Similarly thermally unstable methyl[bis (trimethylsilylsulfano) methylidene] phosphine dimerizes to give the 1,3-diphosphetane 13.6

$\underline{12}$

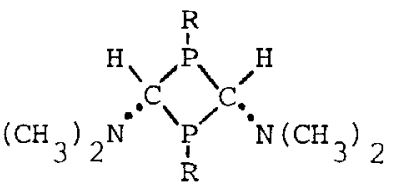

13

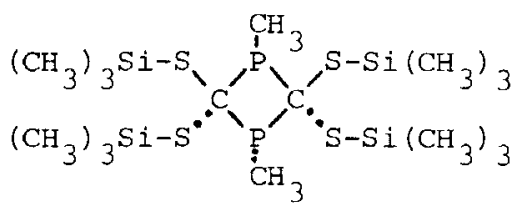

In contact with small amounts of solid sodium hydroxide adducts prepared from alkyl- or arylbis(trimethylsilyl) phosphines and phenylisocyanate or phenylisothiocyanate eliminate hexamethyldisiloxane or bis(trimethylsilyl)sulfane to give very unstable [ (phenylimino) methylidene] phosphines first. In contrast to tertbutyl[(tert-butylimino)methylidene]phosphine recently described by Kolodiazhnyi, ${ }^{7}$ these compounds dimerize immediately to 2,4-bis(phenylimino)-1,3-diphosphetanes 14 (eq. (3)). In case of the<smiles>[R]P=C=NCc1ccccc1</smiles>

ethyl derivative a dimer could be obtained from cyclopentane, a trimer from toluene. ${ }^{4}$

\section{REFERENCES}

1. Summary: G. Becker, W. Becker, and o. Mundt, Phosphorus and Sulfur 14, 267 (1983).

2. G. Becker and W. Uhl, Z. anorg. allg. Chem. 475,35 (1981).

3. G. Becker and G. Gutekunst, $Z$. anorg. allg. Chem. 470, 144 $(1980) ; 470,157$ (1980).

4. G. Becker et al., Z. anorg. allg. Chem., in press.

5. G. Becker, W. Massa, O. Mundt, and R. Schmidt, Z. anorg. allg. Chem. 485, 23 (1982).

6. G. Becker, W. Massa, R. Schmidt, and G. Uhl, Z. anorg. allg. Chem., in press.

7. O.I. Kolodiazhnyi, Tetrahedron Lett. 23, 4933 (1982). 